\title{
Difficultintubationapp.com version 2.0: difficultairwayapp?
}

\author{
James R. Nielsen, BA, MBBS, FANZCA $\cdot$ Kar-Soon Lim, MBBS, FANZCA
}

Received: 13 October 2016/Revised: 6 November 2016/ Accepted: 17 January 2017/Published online: 10 February 2017

(c) Canadian Anesthesiologists' Society 2017

\section{To the Editor,}

Clinical prediction of airway difficulty is often incorrect for endotracheal intubation and its alternatives. ${ }^{1,2}$ The risk of such failure is reduced by checking previous anesthetic charts - if clinicians can access them and if they contain the information required. Unfortunately, charts from other hospitals are frequently inaccessible and the records of airway management incomplete. ${ }^{3}$

Shanahan's clever difficultintubationapp ${ }^{4}$ addresses the first half of this problem. The app produces a letter available on patients' smartphones, so clinicians can access records of a difficult intubation even when the medical records personnel have "gone home." In its current form, however, the app's letter does not contain all the information required.

The success or failure of bag-mask ventilation and laryngeal mask insertion should be emphasized. These techniques are primary rescue maneuvers for difficult intubation, and each deserves a specific section. The authors' example does mention mask ventilation but lists it confusingly, under "preoperative physical characteristics."

Furthermore, the quality of information about rescue techniques should match that given for intubation. Details of the operator's method are useful, but what matters most is outcome - how well it worked in the patient. The authors' example does this for intubation ("grade III with direct laryngoscopy, grade II with C-MAC") but describes

This letter is accompanied by a reply. Please see Can J Anesth 2017; 64: this issue.

J. R. Nielsen, BA, MBBS, FANZCA $(\square) \cdot$ K.-S. Lim, MBBS, FANZCA

Department of Anaesthesia and Pain Management, Concord Repatriation General Hospital, Concord, NSW, Australia e-mail: jamesrnielsen@gmail.com only the method for mask ventilation ("two operators"). The outcome of rescue maneuvers should also be recorded explicitly - not left to inference.

How might one record ventilation maneuvers? We recently described a simple, objective scale based on capnography. ${ }^{5}$ Capnography is a direct, immediate measure of ventilation. Our scale uses four grades (A-D) to describe mask ventilation according to the shape and amplitude of the best capnograph produced (Figure). It enables clinicians to record both method and outcome for mask ventilation (e.g., "grade A capnograph with Guedel airway"). Capnography is also a valid measure of ventilation through a laryngeal mask, and an absent or inadequate capnograph is a sign of difficulty. ${ }^{2} \mathrm{We}$ suggest that the capnography scale could also be used to describe the ventilation outcome when using a laryngeal mask airway (LMA) (e.g., "grade B capnograph with Classic 4").

In summary, difficulty with intubation makes information about its rescue maneuvers critical. Clinicians need to know about the methods and outcomes for intubation, LMA insertion, and mask ventilation. A future version of difficultintubationapp that includes information regarding rescue ventilation would be welcome.

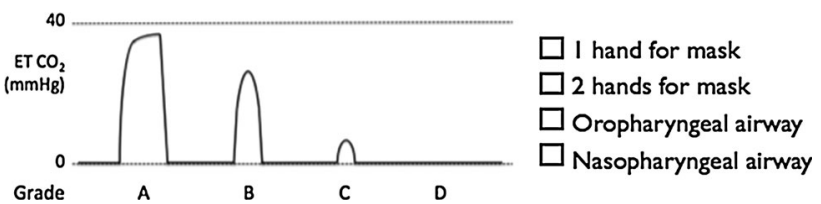

Figure Scale for grading mask ventilation. ${ }^{5}$ Grade A: plateau present; grade B: no plateau, end-tidal (ET) $\mathrm{CO}_{2} \geq 10 \mathrm{mmHg}$; grade C: no plateau, $\mathrm{ETCO}_{2}<10 \mathrm{mmHg}$; grade D: no $\mathrm{ETCO}_{2}$. Reproduced with permission from: Lim KS, Nielsen JR. Objective description of mask ventilation. Br J Anaesth 2016; 117: 828-9. 
Funding \& conflicts of interest declaration This is a letter, written by two colleagues, outside working hours. The work had no funding, internal or external. We have no affiliations or associations, commercial or non-commercial, that create any conflict of interest in relation to this submission (or any other submission).

Editorial responsibility This submission was handled by Dr. Gregory L. Bryson, Deputy Editor-in-Chief, Canadian Journal of Anesthesia.

\section{References}

1. Norskov AK, Rosenstock CV, Wetterslev J, Astrup G, Afshari A, Lundstrom LH. Diagnostic accuracy of anaesthesiologists' prediction of difficult airway management in daily clinical practice: a cohort study of 188064 patients registered in the Danish Anaesthesia Database. Anaesthesia 2015; 70: 272-81.

2. Saito T, Chew ST, Liu WL, Thinn KK, Asai T, Ti LK. A proposal for a new scoring system to predict difficult ventilation through a supraglottic airway. Br J Anaesth 2016; 117(S1): i83-6.

3. McCarty LK, Saddawi-Konefka D, Gargan LM, Driscoll WD, Walsh JL, Peterfreund RA. Application of process improvement principles to increase the frequency of complete airway management documentation. Anesthesiology 2014; 121: 1166-74.

4. Shanahan E, Huang JH, Chen A, Narsimhan A, Tang $R$. Difficultintubationapp.com - A difficult airway electronic record. Can. J Anesth 2016; 63: 1299-300.

5. Lim KS, Nielsen JR. Objective description of mask ventilation. Br J Anaesth 2016; 117: 828-9. 